\title{
Fukushima effects in Germany? Changes in media coverage and public opinion on nuclear power
}

\section{Introduction}

On the $30^{\text {th }}$ of June 2011, the German parliament (Bundestag), with cross-party consensus, made the decision to enact a nuclear phase-out for Germany. As this decision marks a remarkable political shift, it must be interpreted as a direct response to the nuclear disaster that occurred in Japan in March of 2011. The same parliament had made the opposite decision only six months prior, calling for an extension of German nuclear power plants runtime. This raises the following question: Why did such a fundamental political change occur in Germany while several other countries continued and even extended nuclear plans? To understand this political shift in Germany, it is necessary to investigate public debate surrounding nuclear energy in the media and its effects on public opinion. Analysing this specific case, we will discuss general questions and conditions concerning media effects on public attitudes.

We will first review factors that can either limit or evoke strong media effects on attitudes from a theoretical perspective and discuss whether such factors were predominant in Germany when the Fukushima disaster occurred. The second section includes a literature review on nuclear power in the media and in public opinion to derive our research questions. We will then present the methodology and findings of two studies. In the first study, two content analyses were performed, in 2010 and 2011, on nuclear power media coverage in Germany. In the second study, we examine attitude changes caused by the Fukushima accident using a suitable panel survey on energyrelated attitudes. The first survey wave was carried out immediately before the German nuclear runtime extension was enacted in September of 2010, and the second was conducted two months after the Fukushima accident had happened in 2011. Using the 
data of the participants who participated in both waves ( $n=341)$, we examined whether attitude changes had occurred.

\section{Preconditions of persuasive media effects}

In pluralistic democracies, the media system is independent and uncontrolled by the state or by economic stakeholders. As numerous political and societal actors strive to promote their positions, a certain variety of published opinions can be obtained. This variety hinders persuasive media effects, as it allows individuals to avoid messages that are not in line with their existing attitudes and that may provoke cognitive dissonance (Festinger, 1957). A second factor that limits or modifies persuasive effects includes social embedding and social influence effects on individuals via interpersonal communication networks or opinion leaders in their personal environment (Boomgaarden, 2014). A third factor that moderates persuasive media effects concerns audience characteristics, such as interests, motives, involvement and information processing (e.g., Petty, Brinol, \& Priester, 2009; Rubin, 2009).

In contrast to factors that hinder or modify persuasive media effects, several novel approaches support the notion of strong media effects and therefore serve as the theoretical basis for our study. A key model on media effects in modern societies is Ball-Rokeach and DeFleur's (1976) dependency model of media effects. The authors argue that in modern societies, dependency on media information is necessary for individuals' awareness of global affairs. Research shows that this dependency increases in times of social conflict and following the occurrence of unexpected events such as natural disasters or accidents. Under such circumstances, 'the potential for mass media messages to achieve a broad range of cognitive, affective, and behavioral effects will be increased' (Ball-Rokeach \& DeFleur, 1976: 7). These authors’ description of media dependency closely reflects conditions in Germany when the Fukushima tsunami 
occurred. The unexpected accident evoked a national debate on nuclear energy usage, and the media served as the main source of information on this issue. The media dependency model can thus explain why strong media effects could be expected in this particular case.

Another response to the lack of empirical support for the model of strong media effects is Noelle-Neumann's (1973) approach. She identified three relevant factors that facilitate strong effects, as follows: consonance, ubiquity and cumulation. Consonance refers to situations in which mainstream media outlets present and evaluate a controversial issue in a consonant way. Although consonance is uncommon in pluralistic media systems, certain topics may still be covered consonantly in such systems. As the bandwidth of problem definitions and evaluations published by the media is largely determined by the spectrum of political opinions represented in a political establishment (i.e., indexing, Bennett, 1990), consonance is prevalent when major political actors agree regarding the interpretation of a political problem. As an effect of media consonance, audiences will more likely be influenced by the dominant worldview presented by the media, as alternative interpretations are not available. Furthermore, a limited spectrum of opinions may also affect peoples' willingness to speak out (i.e., spiral of silence, Noelle-Neumann \& Petersen, 2004). Depending on whether one's opinion lies inside or outside of the spectrum of published opinion, one will be confronted less or more often with arguments that are consonant or dissonant to one’s own political opinion. If published opinion is predominantly dissenting, fear of isolation increases and the willingness to voice one's own personal opinion in public decreases. Dominant problem definitions can thus also shape the content of interpersonal communication, increasing the ubiquity of a specific worldview even further (Noelle-Neumann \& Petersen, 2004). 
Cumulative effects are considered in numerous novel theories on media effects. A prominent example is the agenda-setting approach, which postulates that the frequency of media coverage on an issue influences the perceived importance of this issue to the public. Furthermore, it is assumed that the selection of issues (first level agenda setting) and especially the selection of attributes (second level agenda setting) will influence public opinion (McCombs \& Reynolds, 2009). Research on agenda setting shows that effects can be observed almost exclusively for unobtrusive issues, or issues that individuals do not have first-hand experiences with (Zucker, 1978). Ball-Rokeach and DeFleur (1976) would state that this situation reflects high media dependency.

If Noelle-Neumann (1973) is correct, we can expect strong media effects if media coverage on nuclear energy following the Fukushima accident was consonant, intense and omnipresent in all media channels. It is thus necessary to examine the amount and content of coverage provided through a broad range of media sources.

\section{Nuclear power in the media and in public opinion}

The following section provides a literature review on media coverage and public opinion on nuclear power. Given the focus of this paper, we predominantly focus on research on Germany. First, we will present content analysis and survey results for the period preceding the Fukushima accident. Then, we will discuss international findings on attitude changes towards nuclear power as a result of the Fukushima accident, which are referred to as Fukushima effects.

\section{Media coverage on nuclear power prior to the Fukushima accident}

To date, only a few long-term studies have examined developments and changes in media coverage on nuclear power (Gamson \& Modigliani, 1989; Kepplinger, 1988; Overhoff, 1984). In the 1950s and 1960s, the media highlighted positive societal, 
technological and economic development fostered through civilian uses of nuclear power (Gamson \& Modigliani, 1989). However, with the rise of social movements in the late 1960s, the thematic focus and evaluation changed. Since then, a negative trend in the German press has induced a fundamental re-evaluation of nuclear power (Kepplinger, 1988). According to Gamson and Modigliani (1989, p. 16), similar trends can be observed in the US, where the media focused more heavily on public accountability, the promotion of environmentally friendly alternatives and the low costeffectiveness of nuclear power. Later, in the context of the oil crisis of the early 1970s, atomic energy was evaluated positively once again. In German and US media outlets, the oil crisis was exploited to promote national energy independence through the use of nuclear energy (Gamson \& Modigliani, 1989; Kepplinger, 1988). However, following this intermezzo, the previous negative trend continued. According to the results of Overhoff (1984), the German press began to cover environmental risks of nuclear power and conflicts between the antinuclear movement and the police more intensively. These critical views were reinforced further in both countries following the nuclear accidents of Three Miles Island (TMI) and Chernobyl in 1979 and 1986, respectively.

Interestingly, studies that examined immediate media responses to these nuclear accidents revealed that the negative evaluation of nuclear energy was not reinforced. Teichert (1987), in examining German media coverage in the first two weeks following the Chernobyl accident, found radiation exposure to be the most prominent issue discussed in media coverage on the accident. However, it was covered with a rather benign rather than alarming tone. Only four percent of all news items noted any risks due to radiation. Stephens and Edison (1982), who analysed the US media coverage released in the first week following the TMI accident, drew similar conclusions. The authors noted that the media did not use the accident to cast doubt on the security of US nuclear power plants in general (Stephens \& Edison, 1982, p. 201). Furthermore, 
Friedman et al.’s (1987) findings show that even after the Chernobyl accident, no reevaluation of radiation exposure took place. Although US media discussed radioactive radiation more often after the accident, the tone remained fairly subdued.

Since the 2007 release of the Stern Report on consequences of climate change, a number of political actors have begun to reframe nuclear power as an effective instrument for tackling climate change. Doyle (2011) analysed the British news coverage from 2005 to 2008 and found that the media initially resisted the government's attempt to reframe atomic energy. However, all newspapers eventually adopted the political discourse and accepted the notion that pursuing nuclear energy is less risky than provoking climate change through the use of fossil fuel resources. Similar findings were obtained by McGaurr and Lester (2009), who examined debates on risks of climate change versus those of nuclear power presented in the Australian press from 2005 to 2007. After the Australian Prime Minister declared climate change to be a national threat in May of 2006, the media began to frame nuclear power as a technical solution to climate change in Australia (McGaurr \& Lester, 2009, p. 183). In the German media, this political reframing can be observed in the government's attempt to legitimize the extension of German nuclear power plants in 2010 (Arlt, 2013).

To understand media effects on attitudes, it is necessary to not only know which thematic aspects were emphasised in the media and how they were evaluated but also which actors advocated for nuclear energy and which held a critical stance. The effects of a message depend not only on its content but also on its author. The results of various studies on German media coverage show consistently that the positions of political actors were cited in the German media. Overhoff (1984) found that politicians were mentioned in more than half of all articles, antinuclear activists and citizens' initiatives were mentioned as relevant actors in only one-third of all articles, and industrial actors followed in third place. Trade unions and scientists were hardly ever mentioned in the 
media. Kepplinger (1988) notes that public opinion in Germany was shaped decisively by politicians and statements made by journalists. In addition, Teichert (1987, p. 198) found that after the Chernobyl accident, national politicians took centre stage in the media. Through their engagement, they attempted to counteract the German population's growing mistrust of nuclear power. Taken together these studies clearly indicate that political actors play an important role in coverage on nuclear energy. However, no findings concerning the actors’ party affiliations are available.

In summary, it can be concluded that the majority of content analyses on nuclear power were conducted in the context of events such as the TMI and Chernobyl accidents and therefore only analysed short periods. With the exception of these case studies, few studies examined media coverage over longer periods or studied nuclear power in a broader context of climate and energy politics, as a number of more recent studies do (Arlt, 2013). Several studies showed that both thematic aspects (attributes) and tendencies vary according to political and historical contexts. Findings on actors who expressed opinions on nuclear power showed that representatives of political administrative systems played an especially dominant role. Given the inherent political aspects of the issue, it can be assumed that media debates on nuclear power following the Fukushima accident will remain more political than economic or scientific.

Based on these assumptions and the above-listed content analysis, we developed categories that measure thematic aspects, tendencies, and actors and pose the following three research questions:

RQ1: How frequently and consonantly did the media cover the issue of nuclear energy? RQ2: Has media coverage on thematic aspects of nuclear power changed since the Fukushima accident? 
RQ3: Have actors covered by the media changed their positions and arguments surrounding nuclear power since the Fukushima accident?

Public opinion on nuclear power in Germany prior to the Fukushima accident Allensbach Institute for Public Opinion Research and Eurobarometer data offer insight into German attitudes on nuclear power prior to the Fukushima accident. In 2005, approximately 64 percent of Germans were convinced that German nuclear power plants were safer than those of other countries, and less than half of the population (46\%) feared a nuclear accident. Approximately half of Germans believed that nuclear energy is cheap and economical (51\%) and helps to preserve fossil energy resources (52\%). However, the German population also recognised several problems. Approximately 80 percent realised that nuclear energy usage creates nuclear waste, and another 72 percent were aware of the unsolved nuclear waste disposal issue in Germany (Schulz, 2006). Findings from a secondary analysis of the German sample $(n=1537)$ of the 2009 Eurobarometer survey data show that attitudes on nuclear energy were strongly influenced by assessments of risks and cost effectiveness. Respondents with positive evaluations of security and cost effectiveness cited more arguments that supported extended nuclear energy usage (Arlt, 2013). Findings from an Allensbach survey that was carried out in March 2010 showed that even shortly before the parliament enacted the runtime extension, the population remained divided on the issue. Specifically, 37 percent of the German population opposed and 44 percent advocated nuclear power. However, only a minority (31\%) believed that the runtime extension was a good proposal, while 43 percent did not (Petersen, 2010). In sum, these results indicate that German public opinion on nuclear power remained divided even while overall representations of nuclear power were predominantly positive.

Fukushima effects 
A number of studies examined the effects of the Fukushima accident on attitudes towards nuclear power. For example, a few days after the Fukushima accident, WINGallup International (2011) carried out a global snap poll of 47 countries to analyse the event's impact on public opinion. Respondents were asked to report their views of nuclear energy before the accident occurred and how their views have changed. The findings reveal a global shift in public opinion. Before the accident, 57 percent were in favour of using nuclear power, and after the event, this value was reduced to 49 percent. Vogel (2014) examined the influence of the Fukushima accident on peoples' attitudes towards risks and the environment using data from the ISSP 2010 - Environment III. As the survey was conducted in certain countries before the Fukushima accident and in others after the event, he observed Fukushima effects through a comparison of these two groups. The results show that risk perceptions and environmental awareness levels were clearly higher following the Fukushima accident. Using independent survey data from before and after the Fukushima accident, Huang et al. (2013) examined changes in the public's risk perception and acceptance of nuclear power plants in China. The authors found that perceived risk levels increased while public acceptance levels decreased significantly. Two panel data studies from Italy and Switzerland reveal significant attitude changes at the individual level. Prati and Zani's (2013) study shows a decline in nuclear trust and pronuclear attitudes. However, the sample included 32 participants and, thus, was very small and unrepresentative. Siegrist and Visschers (2013) examined effects of the Fukushima accident on acceptance of nuclear power and on evaluations of different nuclear phase-out scenarios using panel data of $n=463$ individuals. Although the results revealed a negative Fukushima effect on nuclear power acceptance, in general, the level of acceptance remained relatively stable and high. Regarding the evaluation of various nuclear-phase-out scenarios, the results underline the importance of participants' pre-Fukushima attitudes towards nuclear power. 
Overall, previous studies on attitude changes caused by the Fukushima accident revealed that the event may have changed public opinion on nuclear power.

Nevertheless, the existing research on Fukushima effects is limited. While Siegrist and Visschers' (2013) study based on a panel survey best reflects our approach, the authors do not discuss or analyse the role of the media coverage and use. Most studies relied on cross sectional data; thus, they are unable to identify attitude changes at the individual level, which leads us to our fourth research question:

RQ4: Have people’s attitudes towards nuclear power changed since the Fukushima accident?

If such attitude changes can be observed, questions arise regarding how to explain individual differences in the level of change. According to the risk communication perspective, especially in times of crisis, the media plays an important role as an information source (Pidgeon et al., 2003). In the case of the Fukushima accident, the media served as nearly the sole source of information on this issue among German residents. Hence, the amount of news media exposure may have influenced attitude changes. Furthermore, it is known that attitudes towards nuclear power are influenced by sociodemographic characteristics and basic political and energy-related attitudes (Arlt, 2013). However, it is unclear whether these factors also affect attitude changes. This leads us to our final research question:

RQ5: Which factors can explain changes in attitudes towards nuclear power?

To answer our research questions regarding changes in media coverage, data from two content analyses were used (study 1). In addition, data from two panel surveys were used to study changes in attitudes towards nuclear power (study 2). The following section presents the content analysis and survey methodologies and findings. 


\section{Study 1: Changes in media coverage on nuclear power}

\section{Methods and data}

To answer the first three research questions, two quantitative content analyses were conducted. The media sample included seven information sources, as follows: the three most popular German evening newscasts (ARD Tagesschau, ZDF heute and RTL Aktuell); the two highest circulation and most influential national newspapers (Süddeutsche Zeitung and Frankfurter Allgemeine Zeitung) and, given the regional focus of the project, the two most widely read local newspapers (Thüringer Allgemeine and Freies Wort). The first analysis covered the eight-week period preceding the German parliament nuclear power plant runtime extension (10/07/2010 to 04/09/2010). For this time period, all news items that mentioned either the runtime extension or the cancellation of the nuclear phase-out decision of 2000 were selected. A total of 259 news items were coded. The second analysis covered the first two months immediately following the Fukushima disaster (12/03/2011 to 16/05/2011). As media coverage in 2011 was more frequent, we analysed a sample of this coverage by randomly selecting three days per week. To allow for a meaningful comparison between 2010 and 2011 coverage, articles on the Fukushima incident were only included in the sample if uses of nuclear energy in Germany were discussed. The sample includes 243 news items. The two periods were chosen because both were characterised by frequent media coverage on nuclear energy in Germany.

The coding instrument was created in two steps. In the first step, categories of thematic aspects and evaluative statements were developed based on existing literature. In the second step, the codebook was inductively supplemented. We coded seven categories to examine which thematic aspects of nuclear power were emphasised (table 1).

Furthermore, we coded actors' “evaluative statements on nuclear energy”. Every statement was coded based on the following three categories: actor, position (positive or 
negative) and reasons for the given position. In 2011, we used a nearly identical coding instrument; only a few adaptations were necessary. For example, in 2010, “evaluative statements” referred to statements for or against a runtime extension. In 2011, we coded statements for or against future uses of nuclear power. Consequently, the two items are not completely identical but are comparable in light of political discussions at the time. The reliability test revealed satisfactory results. ${ }^{i}$

Results on changes in media coverage on nuclear power

Regarding the accentuation of thematic aspects, we found some significant changes from 2010 to 2011 (table 1). The analysed media outlets emphasised issues of risk vs. security significantly more often in 2011 than in 2010. Coverage on protests and demonstrations against nuclear power also increased. By contrast, economic issues were discussed significantly less often after the Fukushima accident. We also found a significant but less pronounced decline in coverage on energy supply and environmental compatibility. There were no changes in coverage on renewable energies and climate protection.

Table 1. Changes in the accentuation of thematic aspects in media coverage

Regarding actors’ evaluative statements concerning nuclear power, some shifts, but no fundamental changes, in the distribution of actors were observed. In both periods, government statements dominated: 54 percent of all statements made in 2010 and 45 percent of all statements made in 2011. However, their proportion declined somewhat in the interest of opposition politicians (2010: 17\%; 2011: 23\%) and anti-nuclear activists (2010: 5\%; 2011: 9\%). No changes were observed regarding the number of statements cited from the nuclear industry and the general population. 
We found significant changes in the actors' positions on nuclear energy. While in 2010, less than one-third (31\%) presented strong views against further use of nuclear energy, after the Fukushima accident, almost three-quarters (73\%) argued for a nuclear phaseout. This change is especially evident in statements made by governmental actors. While in 2010, only four percent were opposed to further use of nuclear energy, after the Fukushima accident, 75 percent supported a nuclear phase-out. Similar but less dramatic changes were observed for actors of the economic sector that did not belong to the nuclear industry. The only exception with respect to positioning trends was found for actors of the nuclear sector, who expressed overwhelming support for long-term uses of nuclear energy both before and after the Fukushima accident. Unsurprisingly, the groups that already expressed a clear position against nuclear power in 2010, particularly the opposition and anti-nuclear activists, remained critical in 2011.

In addition to shifts in evaluative positioning, we found changes in actors' justifications of their positions for or against nuclear power. Two findings are of note. First, the proportion of statements that were supported with substantiated arguments declined significantly from 50 percent in 2010 to less than one-third (32\%) in 2011. Clearly, numerous actors considered it less necessary to justify their positions in the context of the nuclear disaster. Second, the thematic focus of justifications changed as well. In the context of runtime extension in 2010, most of the 348 statements citing arguments focused on issues of cost-effectiveness (44\%) and supply security (25\%). After the Fukushima accident occurred, cost-effectiveness was relegated to third place. Arguments concerned with issues of supply security remained prominent (28\%), and the percentage of statements focusing on risk vs. security arguments increased considerably (27\%).

The repositioning of dominant key stakeholder groups also became apparent with respect to the thematic focus of their argumentation (table 2). In 2010, the government 
based its positions mainly on economic arguments. However, in 2011, issues of security and risk were used as justifications. Opposition groups based their arguments on energy supply and risk issues in both years, whereas in 2011, their focus shifted dramatically to arguments that emphasised the risks of nuclear power. The nuclear industry continued to focus its argumentation on economic arguments, stressing this factor even more in 2011. Anti-nuclear movement actors' arguments shifted from questioning issues of costeffectiveness to highlighting security risks. These tendencies were observed in all of the analysed media. While absolute and relative changes varied, the general findings are in agreement.

Table 2. Changes in the thematic argumentation of key actor groups

The detected changes in media coverage provide optimal conditions for strong media effects on peoples' attitudes towards nuclear power. Due to the continuous and intensive media coverage and growing consonance in the actors' negative positioning concerning the future use of nuclear energy, it was difficult for recipients to escape the media's influence via selective media exposure. Therefore, we expect that peoples’ attitudes towards nuclear energy became more negative in 2011. In the following section (study 2), this assumption is tested.

\section{Study 2: Changes in public opinion on nuclear power}

\section{Methods and data}

To examine and explain possible attitude changes, panel survey data from 2010 and 2011 were used. The first wave of telephone surveys was carried out before the runtime extension was enacted by the German parliament (16/08/2010 to 06/09/2010), and the second wave was conducted two months after the Fukushima disaster had occurred 
(15/05/2011 to 04/06/2011). A total of 341 individuals of private households participated in both panel waves. Survey participants (49\% women, 51\% men) were between 19 and 88 years of age (mean age: 52). The sample, which is representative of Thuringia, was selected using a two-stage random method (random-last-digit and nextbirthday) with the support of the German Leibniz Institute for the Social Sciences (GESIS). To compensate for sample distortions, we calculated weighting factors based on the sex and age distributions of the basic population.

To analyse changes in attitudes towards nuclear power, the standardised questionnaire included eight items that were used in both waves of the panel survey (table 3). Given the state of research and political debate in Germany at the time, attitudes towards nuclear energy were examined on three dimensions: a) the environmental compatibility of nuclear power, b) nuclear power security vs. risk and c) the "replaceability" of nuclear power with renewable energy sources. While environmental compatibility was measured using two items that focus on different aspects of the dimension, the security vs. risk and replaceability with renewable energy sources dimensions were each operationalised by three items. Using the six items of dimensions b and c, we conducted a factor analysis for both waves. As expected based on theory, two dimensions were identified.

To explain individual differences in attitude change, the questionnaire also measured the following independent variables: age; sex; education; income; political interest; political left-right orientation; and energy policy-related preferences for environmental compatibility, cost-effectiveness or supply security. ${ }^{\text {ii }}$ From a communication science perspective, it is especially interesting to examine whether attitude changes can be traced to differences in individual media use. We do not expect differential media effects due to consonant media coverage on nuclear power. However, it is plausible that 
individual (topic-related) media exposure and interpersonal communication and quality evaluations of media coverage on energy issues may affect the strength and direction of attitude changes. Given the presence of striking visual representations of the tsunami and exploding reactors in Japan, it can be assumed that individuals who use more visual-based media show stronger changes in the risk dimension which involves especially emotional aspects. By contrast, individuals with a stronger preference for newspapers show stronger attitude changes related to cognitive aspects (replaceability). To prove these assumptions, we considered five variables on media usage and evaluation. ${ }^{\text {iii }}$

Results on changes in attitudes towards nuclear power The results regarding attitude changes, presented in table 3, indicate that in 2010, the missing solutions for the issue of nuclear waste disposal were recognised as serious arguments against nuclear energy. Furthermore, the argument that nuclear energy usage may serve as an appropriate strategy to address climate change was not highly persuasive for the majority of individuals. After the Fukushima disaster, these sceptical views of nuclear energy became even more negative. Security risk evaluation results show that in 2010, most respondents assessed nuclear power as being risky. In line with these findings, the replaceability of nuclear power with renewable energy sources was predominantly assessed as optimistic. After the Fukushima accident occurred, these critical attitudes grew significantly more negative on both dimensions and on nearly all items.

Table 3. Nuclear power attitude changes on three dimensions

Individual attitude changes and possible influencing factors

While these general attitude changes were observed for the entire population, not every individual in the sample changed his or her mind to the same degree. In some cases, 
even opposing changes were identified. An analysis of the panel data revealed that 11 percent of the respondents showed a decline in nuclear risk perceptions, while another 15 percent had growing doubts regarding its replaceability with renewable energy sources. For approximately half of the respondents, no significant attitude changes were observed. Hence, growing risk perceptions and confidence in substitution observed in the aggregate can only be attributed to one-third of the respondents (i.e., those who showed significant attitude changes in this direction). Several respondents had not changed their mind because they already held extremely negative views of nuclear energy prior to the Fukushima accident, rendering it impossible to increase their scepticism further. Correlations between 2010 attitudes and attitude changes indicate that the more positively respondents evaluated atomic energy prior to the Fukushima accident, the higher their observed negative attitude change after the accident. These findings underpin the notion that in the case of the Fukushima accident, German media coverage was consonant so that selective exposure was not feasible, and thus attitude polarisation did not occur.

To explain differences in individual attitude changes, we conducted four regression analyses, in which we tested the influence of nine non-media variables and five media factors. The results show that neither basic political attitudes nor energy policy-related preferences affected the strength and direction of attitude changes (table 4).

Occasionally, some sociodemographic variables such as age and sex had an effect. Furthermore, few and rather small media effects were identified. Consequently, the changes in attitudes can barely be explained by sociodemographic variables and are not attributable to general attitudes. While intensive communication on energy issues resulted in stronger attitude changes in the expected direction, these shifts were weakened by negative evaluations of the quality of media coverage on energy issues. 
Overall, the explanatory power of the models was rather low, reaching a maximum of five percent.

Table 4. Regression models for attitude changes from 2010 to 2011

A more detailed analysis of the hypothesised and observed effects is neither necessary nor illustrative. The central conclusion of these findings is that changes in attitudes were hardly modified by the variables considered. At first glance, this finding appears unremarkable. However, the relevance of this finding increases considerably when we account for the fact that in a cross-sectional analysis with the data from 2010, the same variables can to some extent explain differences in individual attitudes towards nuclear power (table 5).

The results show that individual differences in attitudes are especially influenced by basic political attitudes, energy policy preferences, and sociodemographic variables. It is remarkable that the same factors were irrelevant to attitude changes. Consequently, the significant effects of the cross-sectional study show that non-existent effects revealed through the longitudinal analysis are not trivial. Rather, they illustrate that media coverage on nuclear energy after the Fukushima accident evoked attitude changes that are independent of personal predispositions. This serves as an important precondition for strong media effects.

Table 5. Regression models for differences in attitudes in 2010

\section{Summary and Conclusion}

The aim of this paper was to examine changes in media coverage and in public opinion on nuclear power in Germany as a result of the Fukushima disaster. Findings on 
changes in the accentuation of thematic aspects in the media revealed two trends (RQ2). In 2010, the media reported most heavily on economic issues and less often on security issues of nuclear energy. In 2011, however, the media placed considerably more emphasis on risk vs. security issues and less emphasis on economic topics. Furthermore, changes in the positioning and argumentation of key actors in the media were found (RQ3). The results show that the government and economic sector actors fundamentally changed their positions from predominantly nuclear friendly to predominantly sceptical of nuclear energy. Consequently, political polarization between opposition groups and the government in Germany, which was clearly evident in 2010, largely disappeared following the Fukushima accident. Along with this finding, we identified additional shifts in argumentation trends. In 2011, risk vs. security debates grew more important among all actors. Only the nuclear industry maintained an economically driven pronuclear position.

The panel data analysis further showed that these largely consonant changes (RQ1) in media coverage affected the population. We found attitude changes on three attitude dimensions, environmental compatibility, risk vs. security and replaceability of nuclear energy with renewable energy sources (RQ4). More precisely, the results show that evaluations of environmental compatibility, which were quite negative in 2010, became even more negative after the Fukushima accident occurred. Furthermore, we observed that the assessments of the security of nuclear power grew more negative, and that replaceability with renewable energy was evaluated more favourably. Our interpretation that these changes are indeed effects of media coverage is based on two findings. First, individual attitude changes were not substantially influenced by sociodemographic characteristics, political attitudes, or media exposure (RQ5). Second, the same individual predispositions that had no effect on attitude changes had an effect on the distribution of attitudes according to a cross-sectional perspective. Taken 
together, these two results lead to a plausible conclusion that the observed aggregatelevel attitude changes are a result of ubiquitous and consistent changes in media coverage on nuclear power.

\section{Theoretical conclusions and consequences}

A conclusive investigation of media effects on attitudes is quite a demanding undertaking. When media effects are analysed in experimental laboratory studies, significant doubts typically arise regarding the external validity of findings. Examining media effects in non-experimental field studies, however, is methodologically ambitious and not possible without the use of a combination of various types of data (primarily survey and content analysis data). In using cross-sectional data, it is assumed that issue coverage differences (e.g., nuclear power) among media sources lead to attitude differences among recipients of these different media. Longitudinal studies, however, largely ignore differences between media sources and tend to focus on the aggregate level. This approach presumes that long-term cross-media changes more heavily influence media effects and thus that differences between media sources can be ignored.

The present study combines the two approaches. With the data used here, we examined individual attitude changes and changes in the media coverage of different media sources. The results showed that media coverage was largely consonant with regards to nuclear energy and, above all, that changes in the media coverage were rather uniform. Consequently, we expected uniform attitude effects that do not vary among recipients of different media sources. Indeed, we found significant attitude changes on all attitude dimensions, supporting the assumption that changes can be attributed to media coverage. 
For a theoretical classification of these findings in the context of media effects theory, it must be noted that in the present case, preconditions for media effects were almost fully realised:

- The accident triggered extensive media coverage with a clear negative scope before the second survey was carried out in 2011.

- The media reported ubiquitously and intensively on the issue.

- Obvious and consonant changes in media coverage across different media sources were observed.

- Whereas the media presented differences in the positioning of various actors in 2010, these differences largely disappeared in 2011.

- Alternative information sources, especially direct experiences and interpersonal communication, played no role.

Despite these ideal conditions, we found only small attitude effects (approximately 0.3 scale points on a 4-point scale). Thus, even under nearly perfect conditions for strong media effects, the observed impact was only moderate. Furthermore, it must be noted that only a minority of respondents changed their minds. Most respondents maintained their original attitudes, and some even switched their attitudes in the opposite direction. Taking these findings into account, it is not reasonable to assume that strong media effects on public opinion are commonplace, and they are clearly less likely when coverage is more diverse, as in this particular case.

However, public debate on nuclear power in Germany has a long history, and many of the respondents already had relatively stable attitudes on the issue prior to the surveys. As established attitudes render attitude shifts unlikely, the observed moderate effects are quite remarkable. 
The political decision to quickly withdraw the runtime extension and the usage of nuclear power was supported with broad consensus in politics and in the media. In prior public discourse, and especially among the citizens examined here, nuclear power was a controversial issue. Changes in media coverage following the Fukushima accident reinforced this tenor, albeit slightly. The fact that only small effects were observed despite consonant reporting on the accident raises questions of whether these changes are enduring or whether people may simply change their views again.

Many political decisions associated with the nuclear phase-out and energy policy change, e.g., the construction of wind turbines and additional power lines, are also highly controversial and accompanied by public protest. In addition, there are technical barriers to guaranteeing a secure energy supply that increasingly relies on fluctuating renewable energy sources. Furthermore, renewable energy usage is blamed for rising energy prices. For all of these reasons, political actors who call for a re-evaluation of nuclear power may find support from the population and the media. Even after the Fukushima incident, it is hasty to expect nuclear energy to fully disappear from the German energy portfolio. This was reflected in the respondents' opinions in 2011, as nearly 60 percent agreed that the decision to phase out nuclear energy will end in failure.

\section{References}

Arlt, D. (2013 ). Laufzeitverlängerung von Atomkraftwerken - Nein, Danke!? Der Einfluss medialer Kommunikation auf Einstellungen zur Atomkraft. In J. Wolling, O. Quiring, H. Bonfadelli \& M. S. Schäfer (Eds.), Nachhaltigkeits-, Energie-, und Umweltkommunikation (Band 1). Ilmenau: Univ.-Verl. Ilmenau.

Ball-Rokeach, S. J., \& DeFleur, M. L. (1976). A Dependency Model of Mass-Media Effects. Communication Research, 3(1), 3-21.

Bennett, W. L. (1990). "Toward a Theory of Press-State Relations in the United States." Journal of Communication(2): 103-125. 
Boomgaarden, H. G. (2014). Interpersonal and mass mediated political communication. Political Communication. C. Reinemann. Berlin/Boston, Walter de Gruyter: 469-488.

Doyle, J. (2011). Acclimatizing nuclear? Climate change, nuclear power and the reframing of risk in the UK news media. International Communication Gazette, 73(1-2), 107-125.

Festinger, L. (1957). A Theory of Cognitive Dissonance. Stanford Univ. Press.

Friedman, S. M., Gorney, C. M., \& Egolf, B. P. (1987). Reporting on Radiation: A Content Analysis of Chernobyl Coverage. Journal of Communication, 37(3), 5879.

Gamson, W., \& Modigliani, A. (1989). Media Discourse and Public Opinion on Nuclear Power: A Constructionist Approach. The American Journal of Sociology, 95(1), 1-37.

Holsti, O. R. (1969). Content Analysis for the Social Sciences and Humanities. Reading, MA: Addison Wesley.

Huang, L., Zhou, Y., Han, Y., Hammitt, J. K., Bi, J., \& Liu, Y. (2013). Effect of the Fukushima nuclear accident on the risk perception of residents near a nuclear power plant in China. Proceedings of the National Academy of Sciences, 110(49), 19742-19747.

Kepplinger, H. M. (1988). Die Kernenergie in der Presse. Zum Einfluss subjektiver Faktoren auf die Konstruktion der Realität. Kölner Zeitschrift für Soziologie und Sozialpsychologie, 40, 659-683.

Kim, Y., Kim, M., \& Kim, W. (2013). Effect of the Fukushima nuclear disaster on global public acceptance of nuclear energy. Energy Policy, 61, 822-828.

McCombs, M. E., \& Reynolds, A. (2009). How the Media Shapes our Civic Agenda. In J. Bryant \& D. Zillmann (Eds.), Media Effects. Advances in Theory and Research (3 ed., pp. 1-16). Mahwah, NJ: Erlbaum.

McGaurr, L., \& Lester, L. (2009). Complementary Problems, Competing Risks: Climate Change, Nuclear Energy and The Australian. In T. Boyce \& J. Lewis (Eds.), Climate Change and the Media (pp. 174-185). New York, NY [u.a.]: Lang.

Noelle-Neumann, E. (1973). Kumulation, Konsonanz und Öffentlichkeitseffekt. Ein neuer Ansatz zur Analyse der Wirkung der Massenmedien. Publizistik, 18(1), 26-55. 
Noelle-Neumann, E., \& Petersen, T. (2004). The Spiral of Silence and the Social Nature of Man. In L. L. Kaid (Ed.), Handbook of Political Communication Research (pp. 339-356). Mahwah, New Jersey, London: Lawrence Earlbaum.

Overhoff, K. (1984). Die Politisierung des Themas Kernenergie. Regensburg: Roderer.

Petersen, T. (2010). Wenig Aufregung um die Kernenergie. Dokumentation des Beitrags in der Frankfurter Allgemeinen Zeitung Nr. 70 vom 24. März 2010: Institut für Demoskopie Allensbach.

Petty, R. E., Brinol, P., \& Priester, J. R. (2009). Mass Media Attitude Change: Implications of the Elaboration Likelihood Model of Persuasion. In J. Bryant \& D. Zillmann (Eds.), Media Effects. Advances in Theory and Research (3 ed., pp. 125-164). Mahwah, NJ: Erlbaum.

Pidgeon, Nick/Kasperson, Roger E./Slovic, Paul (2003): The Social Amplification of Risk. Cambridge: Cambridge Univ. Press.

Prati, G., \& Zani, B. (2013). The Effect of the Fukushima Nuclear Accident on Risk Perception, Antinuclear Behavioral Intentions, Attitude, Trust, Environmental Beliefs, and Values. Environment and Behavior, 45(6), 782-798.

Rubin, A. M. (2009). The Uses-and-Gratifications Perspective of Media Effects. In J. Bryant \& M. B. Oliver (Eds.), Media Effects. Advances in Theory and Research (3 ed., pp. 165-184). New York: Routledge.

Schulz, R. (2006). Die Akzeptanz der Kernenergie in Deutschland in längerfristiger Perspektive. Energiewirtschaftliche Tagesfragen, 56(10), 34-37.

Siegrist, M., \& Visschers, V. H. M. (2013). Acceptance of nuclear power: The Fukushima effect. Energy Policy, 59(0), 112-119.

Stephens, M., \& Edison, N. G. (1982). News Media Coverage of Issues During the Accident at Three-Mile Island. Journalism Quarterly, 59(2), 199-259.

Teichert, W. (1987). Tschernobyl in den Medien. Ergebnisse und Hypothesen zur Tschernobyl-Berichterstattung. Rundfunk und Fernsehen, 35(2), 185-204.

Vogel, D. (2014). Der Einfluss der Reaktorkatastrophe auf das nukleare Risikobewusstsein und das allgemeine Umweltbewusstsein in der Bevölkerung. In J. Wolling \& D. Arlt (Eds.), Fukushima und die Folgen. Medienberichterstattung, Öffentliche Meinung, Politische Konsequenzen (pp. 323-340). Ilmenau: Univ.-Verl. Ilmenau. 


\section{Zucker, H. G. (1978). The Variable Nature of News Media Influence. In B. D. Rubin (Ed.), Communication Yearbook 2 (pp. 225-240). New Brunswick: Transaction Publishers.}

\footnotetext{
i To ensure intercoder reliability, we calculated reliability coefficients using the Holsti formula (Holsti, 1969). A reliability coefficient of 0.74 denotes agreement in 74 percent of the codes. The following coefficients were calculated for the different categories: economy (0.74), energy supply (0.76), renewable energy (0.91), risk vs. security (0.84), environmental compatibility (0.88), climate protection (0.92), protests/demonstrations (0.89), actors (0.71), positions (0.72), and justifications (0.68).
}

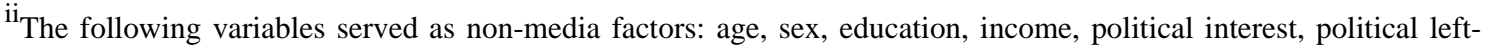
right orientation, and energy policy-related preferences. The latter are based on the following operationalisation: "Germany has various energy policy objectives that are all very important: a) cost-effectiveness, referring to cheap and competitive energy, b) security supply, denoting a sufficient energy supply at all times, and c) environmental compatibility, meaning that energy supplies should preferably cause little environment damage. Which of the three objectives is most important and which comes in second place?" Based on these items, measures of costeffectiveness, security supply and environmental compatibility were calculated.

iii The following variables served as media factors: overall media exposure and media preference. First, the frequency of newspaper, television news, TV magazine, print magazine and online media use was assessed. Then, these indicators were combined into an overall index of media exposure and into an index that operationalises preferences for print or TV media. Energy-related communication behaviours formed an index constructed from the following three items: How often have you noticed news items on issues of energy, climate or the environment over the past year? How often have you purposefully informed yourself on issues of energy, energy consumption or energy saving over the past month? How often have you discussed issues of energy, climate or the environment with friends, relatives or colleagues over the past year? Responses were measured on a five-point frequency scale ranging from "never" to "very often". Evaluations of media quality were measured based on three items on a 4-point agreement scale, in which two dimensions were differentiated. The degree to which the media were considered informative was assessed based on two items ("The media report too infrequently on different energy sources" and "The media report too infrequently on new ways of saving energy"), and neutrality was assessed based on one item ("The media report too dramatically on issues of energy supply"). 
Table 1: Changes in the accentuation of thematic aspects in media coverage

\begin{tabular}{lllr}
\hline \multirow{2}{*}{$\begin{array}{l}\text { thematic aspects of } \\
\text { nuclear power }\end{array}$} & $\begin{array}{l}2010 \\
\text { before runtime decision }\end{array}$ & $\begin{array}{l}2011 \\
\text { after Fukushima accident }\end{array}$ & $\mathrm{p}$ \\
\cline { 2 - 4 } & $\%$ & $\%$ & $<.001$ \\
\hline economy & 73 & 52 & $<.05$ \\
energy supply & 62 & 51 & $\mathrm{~ns}$. \\
renewable energies & 46 & 42 & $<.001$ \\
risk vs. security & 36 & 59 & $<.01$ \\
environmental compatibility & 15 & 7 & $\mathrm{~ns}$. \\
climate protection & 17 & 13 & $<.01$ \\
protests/demonstrations & 16 & 28 & 243 \\
\hline Sum of news items (n) & 259 & 243 &
\end{tabular}

Reading instruction: In 2010, the media mentioned nuclear power economic issues in 73 percent of the 259 news items. In 2011, these references accounted for 52 percent of the 243 news items. 
Table 2: Changes in the thematic argumentation of key actor groups

\begin{tabular}{lrrrrrrrr}
\hline & \multicolumn{1}{c}{ government } & \multicolumn{2}{c}{ opposition } & \multicolumn{2}{c}{ nuclear industry } & \multicolumn{2}{c}{$\begin{array}{c}\text { anti-nuclear } \\
\text { movement }\end{array}$} \\
\hline year & 2010 & 2011 & 2010 & 2011 & 2010 & 2011 & 2010 & 2011 \\
arguments (n) & 165 & 53 & 23 & 9 & 31 & 15 & 15 & 7 \\
\hline & $\%$ & $\%$ & $\%$ & $\%$ & $\%$ & $\%$ & $\%$ & $\%$ \\
\hline cost-effectiveness & 66 & 19 & 17 & 11 & 58 & 67 & 53 & 0 \\
supply security & 26 & 43 & 44 & 22 & 36 & 27 & 33 & 29 \\
risk vs. security & 8 & 38 & 39 & 67 & 6 & 7 & 13 & 71 \\
\hline
\end{tabular}

Reading instruction: In 2010, government actors used cost-effectiveness arguments to justify their positions on nuclear power in 66 percent of their 165 statements. 
Table 3: Attitude changes on nuclear power on three dimensions

\begin{tabular}{|c|c|c|c|c|}
\hline & & 2010 & 2011 & \\
\hline Operationalisation & $\mathrm{n}$ & $\mathrm{M}^{1}$ & $\mathrm{M}^{1}$ & $\mathrm{p}$ \\
\hline \multicolumn{5}{|l|}{ evaluation of environmental compatibility } \\
\hline $\begin{array}{l}\text { As long as nuclear waste disposal issues have not been resolved, a } \\
\text { runtime extension (2010)/longer usage (2011) is irresponsible. }\end{array}$ & 329 & 3.4 & 3.5 & $\leq .01$ \\
\hline $\begin{array}{l}\text { Using nuclear energy is an appropriate strategy for tackling climate } \\
\text { change. }\end{array}$ & $164^{2}$ & 2.3 & 2.0 & $\leq .01$ \\
\hline evaluation of risks (index) & 341 & 2.7 & 3.0 & $\leq .001$ \\
\hline I am concerned about the safety of nuclear power plants. & 337 & 3.1 & 3.3 & $\leq .001$ \\
\hline I feel threatened by the use of nuclear power. & 333 & 2.2 & 2.5 & $\leq .001$ \\
\hline The risk of longer use of nuclear power is too big. & 326 & 2.9 & 3.2 & $\leq .001$ \\
\hline evaluation of replaceability with renewable energy sources (index) & 337 & 2.7 & 2.9 & $\leq .001$ \\
\hline $\begin{array}{l}\text { Without energy from nuclear power plants, energy needs in Germany } \\
\text { will not be covered in the long term (denial). }\end{array}$ & 290 & 2.5 & 2.9 & $\leq .001$ \\
\hline In the long term, renewables will be cheaper than nuclear energy. & 258 & 3.0 & 3.1 & .11 \\
\hline $\begin{array}{l}\text { In the next } 20-40 \text { years, we will establish enough renewable energy } \\
\text { sources to disclaim nuclear energy. }\end{array}$ & 328 & 2.6 & 2.9 & $\leq .001$ \\
\hline
\end{tabular}

Reading example (first line): Average agreement with the first statement increased significantly ( $p \leq .01$ ) from 3.4 in 2010 to 3.5 in $2011 .{ }^{1}$ Average agreement with a four-step agreement scale of 1 ('do not agree at all') to 4 ('agree completely'); ${ }^{2}$ due to a split in the questionnaire, only a random $50 \%$ of the respondents were questioned on this item. Therefore the two items measuring the environmental compatibility were not included in the factor analysis. 
Table 4: Regression models of attitude changes from 2010 to 2011

\begin{tabular}{|c|c|c|c|c|}
\hline & $\begin{array}{r}\text { evaluation } \\
\text { of risks }\end{array}$ & $\begin{array}{r}\text { replaceability } \\
\text { with } \\
\text { renewables } \\
\end{array}$ & $\begin{array}{r}\text { nuclear } \\
\text { waste } \\
\text { problems }\end{array}$ & $\begin{array}{r}\text { strategy to } \\
\text { tackle climate } \\
\text { change }\end{array}$ \\
\hline number of cases $(n)$ & 336 & 324 & 328 & 163 \\
\hline \multirow[t]{2}{*}{ adjusted $\mathrm{R}^{2}$} & .05 & .04 & .05 & .03 \\
\hline & \multicolumn{4}{|c|}{ beta-coefficients } \\
\hline sex (female) & .13 & & & \\
\hline age (high) & & & .19 & .17 \\
\hline energy-related communication (intensive) & .11 & & .11 & \\
\hline newspaper vs. TV preference (newspaper) & & .16 & & \\
\hline quality evaluation: informative (negative) & -.15 & & & \\
\hline quality evaluation: neutrality (negative) & & -.12 & & \\
\hline
\end{tabular}

Notes: All model coefficients are statistically significant at $p<.05$. 
Table 5: Regression models for attitude differences in 2010

\begin{tabular}{|c|c|c|c|c|}
\hline & $\begin{array}{r}\text { evaluation } \\
\text { of risks }\end{array}$ & $\begin{array}{r}\text { replaceability } \\
\text { with } \\
\text { renewables }\end{array}$ & $\begin{array}{r}\text { nuclear } \\
\text { waste } \\
\text { problems }\end{array}$ & $\begin{array}{r}\text { strategy to } \\
\text { tackle climate } \\
\text { change }\end{array}$ \\
\hline number of cases $(n)$ & 336 & 338 & 301 & 165 \\
\hline \multirow[t]{2}{*}{ adjusted $R^{2}$} & .23 & .04 & .12 & .16 \\
\hline & \multicolumn{4}{|c|}{ beta-coefficients } \\
\hline sex (female) & .19 & & & .21 \\
\hline age (high) & .27 & & & \\
\hline political interest (high) & & .12 & .17 & \\
\hline political orientation (left) & & & .12 & \\
\hline $\begin{array}{l}\text { energy political preference: } \\
\text { environmental compatibility (high) }\end{array}$ & .24 & .15 & .23 & .23 \\
\hline energy-related communication (intensive) & -.13 & & & \\
\hline newspaper vs. TV preference (newspaper) & .18 & & .13 & \\
\hline quality evaluation: informative (negative) & .16 & & & 19 \\
\hline
\end{tabular}

Notes: All model coefficients are statistically significant at $p<.05$. 